\title{
A3 Subscale Rocket Hot Fire Testing
}

\author{
G.P. Saunders ${ }^{1}$ and J. Yen ${ }^{2}$ \\ Jacobs Technology, Tullahoma, TN, 37388
}

\begin{abstract}
This paper gives a description of the methodology and results of J2-X Subscale Simulator (JSS) hot fire testing supporting the A3 Subscale Diffuser Test (SDT) project at the E3 test facility at Stennis Space Center, MS (SSC). The A3 subscale diffuser is a geometrically accurate scale model of the $\mathbf{A 3}$ altitude simulating rocket test facility. This paper focuses on the methods used to operate the facility and obtain the data to support the aerodynamic verification of the $A 3$ rocket diffuser design and experimental data quantifying the heat flux throughout the facility. The JSS was operated at both $80 \%$ and $100 \%$ power levels and at gimbal angle from 0 to 7 degrees to verify the simulated altitude produced by the rocketrocket diffuser combination. This was done with various secondary GN purge loads to quantify the pumping performance of the rocket diffuser. Also, special tests were conducted to obtain detailed heat flux measurements in the rocket diffuser at various gimbal angles and in the facility elbow where the flow turns from vertical to horizontal upstream of the $2^{\text {nd }}$ stage steam ejector.
\end{abstract}

\section{Nomenclature}

SSC = Stennis Space Center, MS

$S D T=$ Subscale Diffuser Test Project

$E 3 C 1=$ Refers to test cell 1 at test facility E3 at the E-complex at SSC

$E 3 C 2=$ Refers to test cell 2 at test facility E3 at the E-complex at SSC

$L H=$ Liquid Hydrogen

LOX = Liquid Oxygen

GH $\quad=$ Gaseous Hydrogen

JSS $\quad=\mathrm{J} 2-\mathrm{X}$ Subscale Simulator

\section{Introduction}

T

HIS document provides a description of the methodology and results of J2-X rocket engine Subscale Simulator (JSS) hot fire testing supporting the A3 Subscale Diffuser Test (SDT) project at the E3 test facility at Stennis Space Center, MS (SSC). The A3 subscale diffuser is a geometrically accurate scale model of the A3 altitude rocket test facility. A description of the design of the subscale facility is available in Reference 1 . This paper focuses on the methods used to operate the facility and obtain data to support the aerodynamic verification of the A3 rocket diffuser design and experimental data quantifying the heat flux throughout the facility. The JSS was operated at both $80 \%$ and $100 \%$ power levels and at gimbal angles from 0 to 7 degrees to verify the simulated altitude produced by the rocket-rocket diffuser combination. These tests were conducted with various gaseous nitrogen (GN) test cell purge flows to quantify the secondary flow pumping performance of the rocket diffuser. Also, special tests were conducted to obtain detailed heat flux measurements in the rocket diffuser at various gimbal angles and in the facility elbow where the flow turns from vertical to horizontal upstream of the $2^{\text {nd }}$ stage steam ejector.

\section{Hot Fire Test Procedure}

Rocket diffuser performance testing required the operation of both the steam generator at $\mathrm{E} 3 \mathrm{C} 2$ and the firing of the J2-X simulator (JSS) rocket housed at E3C1. The $2^{\text {nd }}$ stage (z-stage) ejector feed valve is preset to achieve nominal $2^{\text {nd }}$ stage ejector plenum pressure while the $1^{\text {st }}$ stage ejector is set a fixed position prior to starting the steam generator in $\mathrm{E} 3 \mathrm{C} 2$. The $1^{\text {st }}$ stage valve is set to overdrive the $1^{\text {st }}$ stage ejector to minimize system heat up time. The

${ }^{1}$ A3 Subscale Test Project Manager, Advanced Technology Segment, 600 William Northern Blvd., Tullahoma, TN, 37388, Senior Member.

${ }^{2}$ Senior Engineer, Advanced Technology Segment, 600 William Northern Blvd., Tullahoma, TN, 37388, Member. 
steam generator is then started to produce superheated steam. Once superheated steam temperatures are obtained in the ejector plenums, the E3C1 sequence is initiated to for the JSS. A schematic of the test facility is shown in Figure 1.

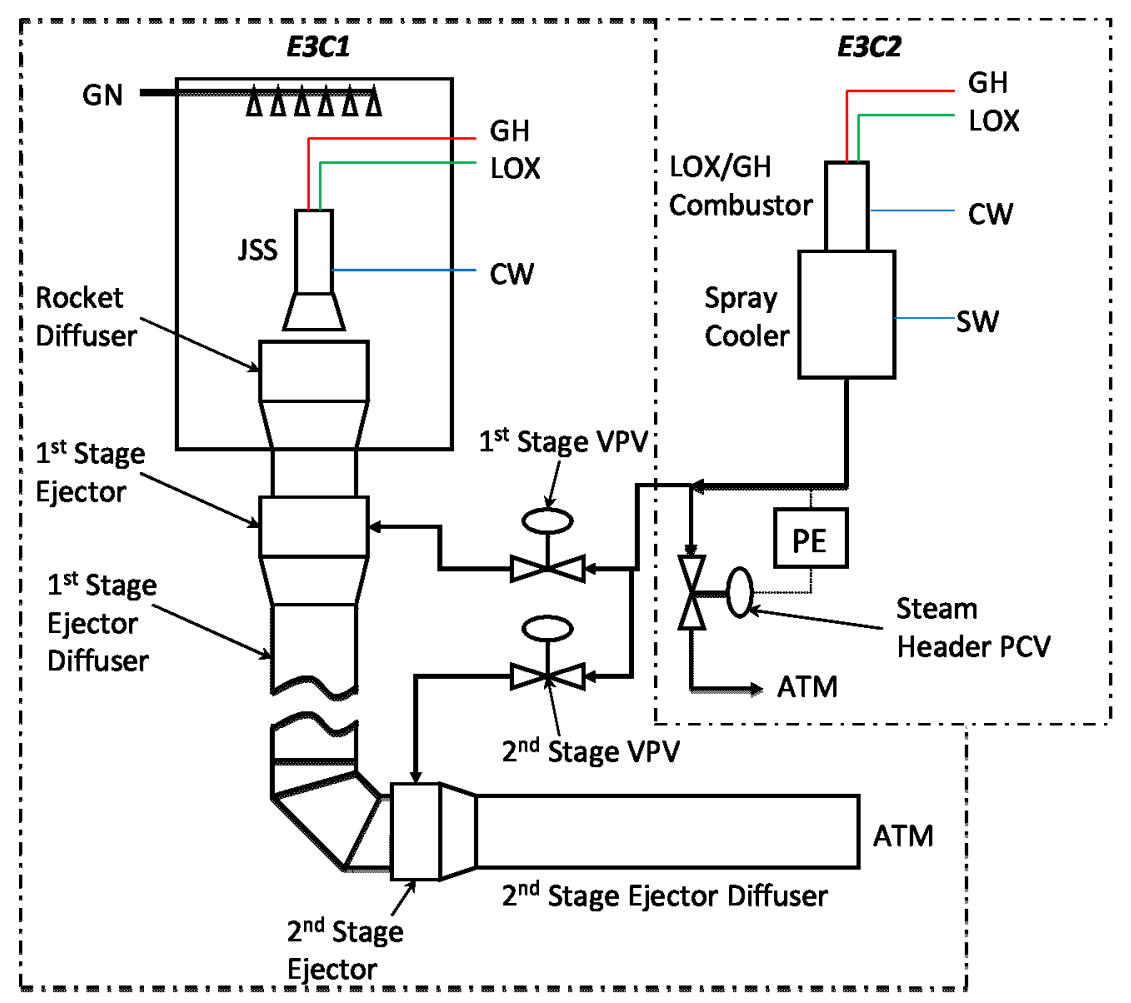

Figure 1. Schematic of E3C1 and $\mathrm{E3C2}$

To fire the JSS, an initial test cell purge and LOX bleed through the engine is utilized to obtain cryogenic temperatures at the injector interface. Simultaneously, the $1^{\text {st }}$ stage ejector feed valve is moved to obtain the desired altitude simulating test cell pressure. The test cell purge is shutoff and the JSS is then fired for approximately five seconds. The use of the GOX/GH spark ignition system allows the JSS to be restarted up to three times during one steam run. JSS firings occur at $\mathbf{3 0}$ second intervals to allow water injection into the diffuser between firings to cool the exhaust train elbow back to ambient temperature. Rocket diffuser performance testing has been performed in the vertical orientation and at engine gimbal angles of 3.5 and 7 degrees in three directions (north, south, and west). Note that the facility exhaust is due north.

Exhaust train heat flux data is obtained in conjunction with rocket diffuser aerodynamic testing. High response surface thermocouples are used to obtain transient inner pipe wall surface temperature used to calculated heat flux. There are 29 available high response thermocouple channels, therefore thermocouples are moved test-to-test to obtain axial and circumferential heat flux distribution data with particular attention paid to the high heat flux regions in the elbow and rocket diffuser. Also, temperature indicating paint is used on the external surface of the diffuser elbow and the internal surface of the rocket diffuser to identify high heat flux regions and thus aid in required placement of thermocouples in maximum heat flux regions.

Initially heat flux calculations were performed assuming that the surface thermocouple assembly behaves as a semi-infinite solid during the test duration. After more detailed analysis, a numerical procedure was developed that considers finite diffuser wall thickness and temperature dependent thermal properties of the thermocouple and diffuser wall material. In either case, the thermal properties of the thermocouple must be similar to those of the pipe wall. A detailed description of the data analysis techniques and test results are available in References 2 and 3. A typical time trace of a JSS hot fire test is shown in Figure 2. 


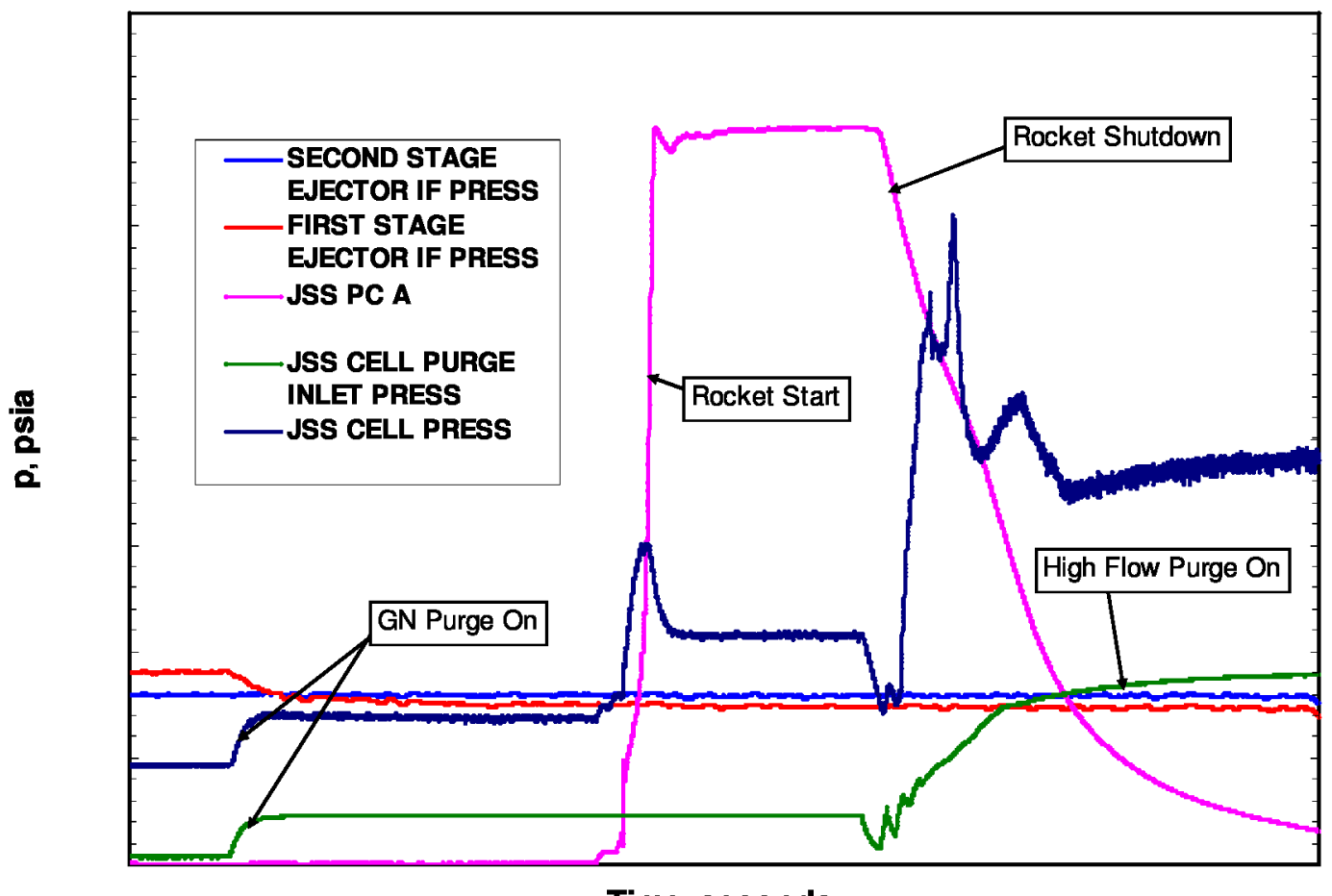

Time, seconds

Figure 2. Typical JSS Hot Fire Time Trace

\section{Aerodynamic Performance Testing}

Initial testing indicated a higher than expected test cell pressure during rocket firing exceeded facility requirements. It was discovered than during initial test runs, the gaseous nitrogen purge system shutoff valve feeding the test cell was leaking (see Figure 2) and there was discontinuity in the joint between the rocket combustion chamber liner and the rocket nozzle extension (A description of the JSS design and activation can be found in Reference 4). The joint discontinuity was repaired and the GN feed system was isolated from the test cell. Subsequent testing showed a test cell pressure below that required and factor of four lower than during initial testing.

Testing at various GN secondary flows followed. Figure 3 shows the secondary suction pressure ratio normalized by the suction pressure at zero secondary flow versus the secondary flow to rocket mass flow ratio. Testing revealed that the test cell pressure is more sensitive to GN secondary flow while the rocket is firing as compared to the facility ejectors operating alone. Aerodynamic performance of the ejector system is described in Reference 5.

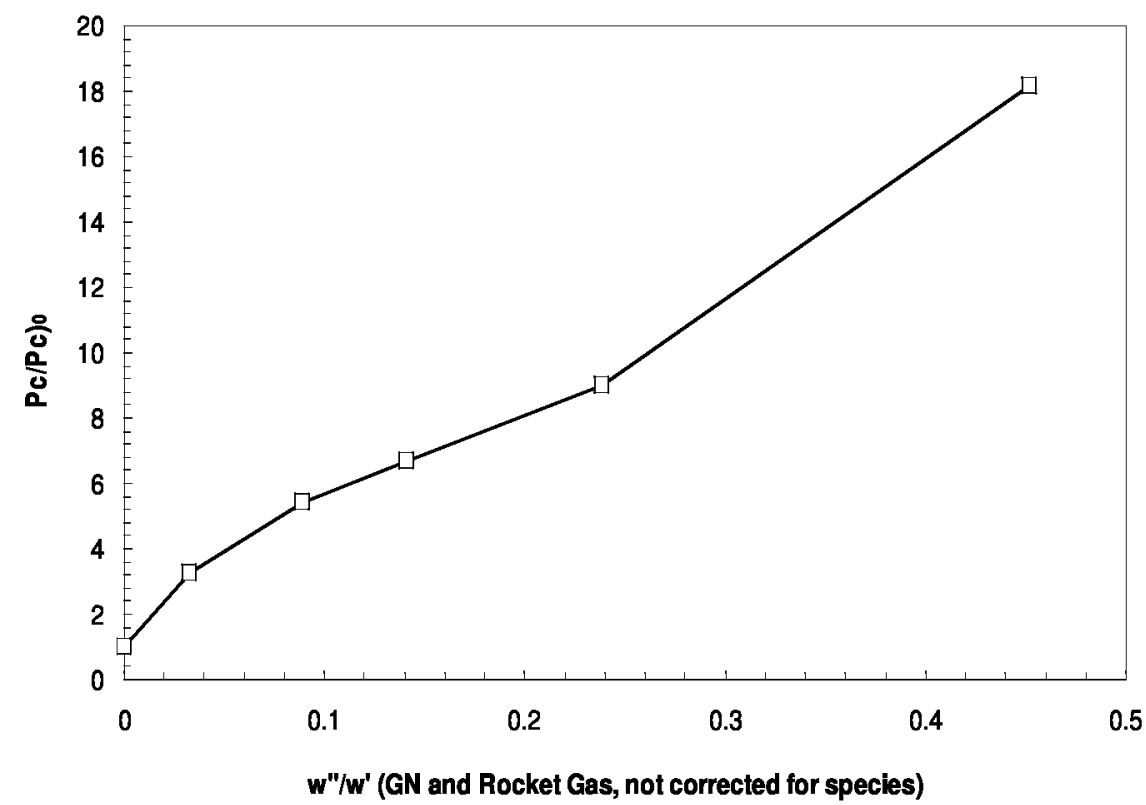

Figure 3. Rocket Diffuser Secondary Pumping Performance

American Institute of Aeronautics and Astronautics 
After secondary flow testing was performed, the JSS mounting structure inside the test cell was modified to allow manual gimbal angle changes to be made between test firings. Figure 4 shows the gimbal mounting structure and JSS installed in the test cell. The gimbal mounting hardware was designed so that temporary cross bracing could be installed to enable gimbal in both the north-south and east-west directions. All gimbal testing was conducted with zero secondary flow. Figure 5 shows the test cell pressure with the rocket firing in vertical orientation and at 3.5 and 7 degrees toward the south.

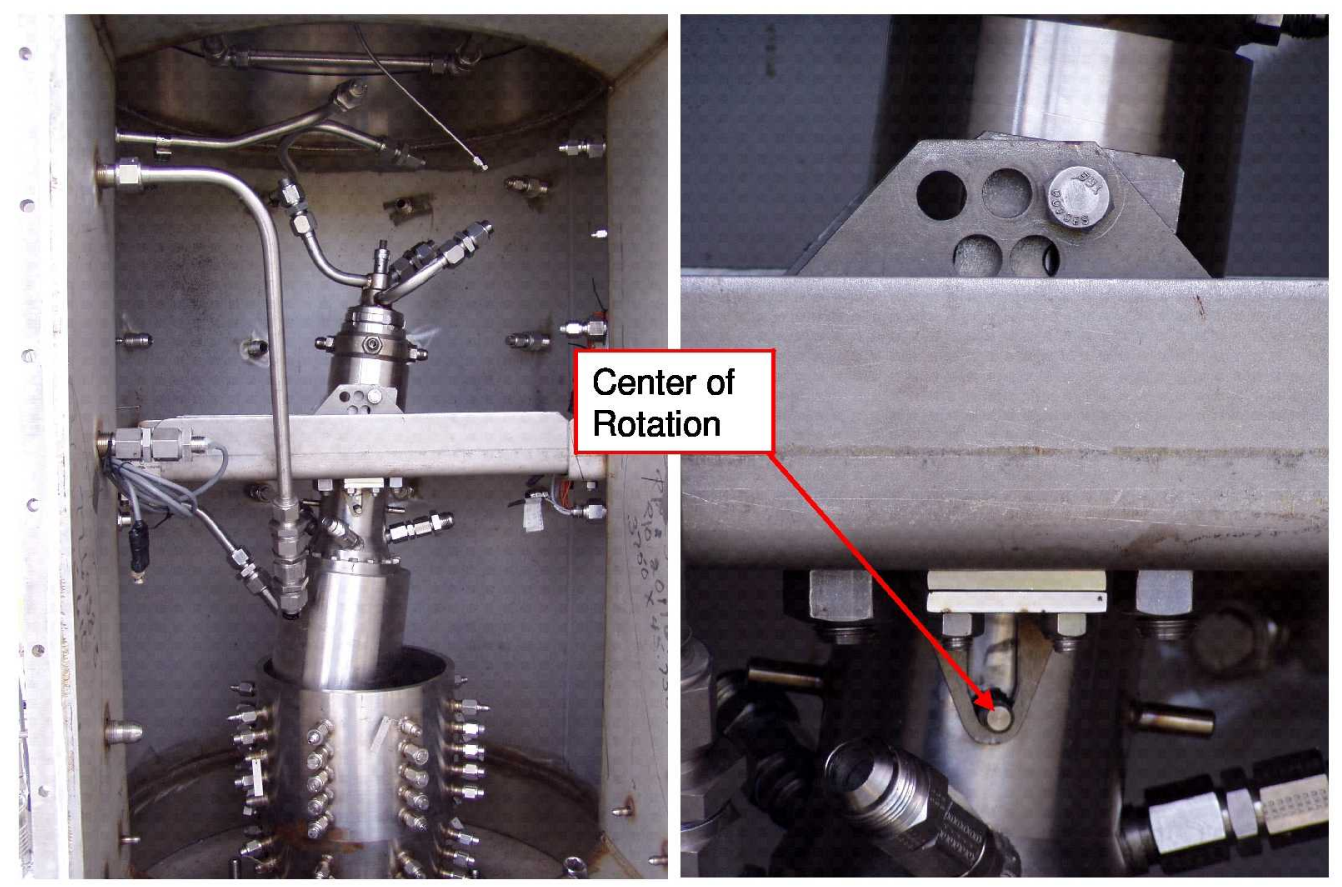

Figure 4. Photo of JSS Installed at Gimbal Angle of 7 degrees

One interesting finding during gimbal testing was a slow test cell pressure rise at a gimbal angle of 3.5 degrees and shown in Figure 5. Though not well understood, it is believed to be caused by coincidence of the rocket plume boundary and the compression corner of the rocket diffuser contraction on the far side of the plume (the north side when gimbal direction is to the south), allowing a small amount of rocket exhaust to spill back into the test cell increasing the test cell pressure. The test cell temperature was not affected indicating that the amount of gas spilled is insignificant. This phenomenon is believed to be unique to the subscale facility and not applicable to the full scale facility. Subscale tests were started and operated at a fixed gimbal angle. In full scale flight engine testing, the rocket is always started in the vertical orientation and then rotated rapidly by large hydraulic actuation systems; therefore, any plume coincidence with the compression corner will occur during transient operation only.

The dip in test cell pressure at rocket start and shutdown in Figure 5 occurs because the flows of engine purges and non-combusting propellants pre and post main stage are high enough to start the rocket diffuser prior to ignition and during shutdown. The presence of a high GN test cell purge prevented this slump during secondary flow testing as indicated in Figure 2. The aerodynamic performance of the rocket diffuser exceeded the facility test pressure requirement at all gimbal angles tested.

A small "lipstick" camera is installed in the test cell to monitor the JSS. It has proved to be a very valuable indicator of rocket performance. A photo of the rocket plume taken by the test cell camera is shown in Figure 6 . The view is looking down through the rocket diffuser from above the nozzle exit plane. The $1^{\text {st }}$ stage ejector nozzle plumes can be seen just aft of the rocket diffuser throat while recompression of the rocket gas is shown the bright region at the inlet of the diffuser elbow. 


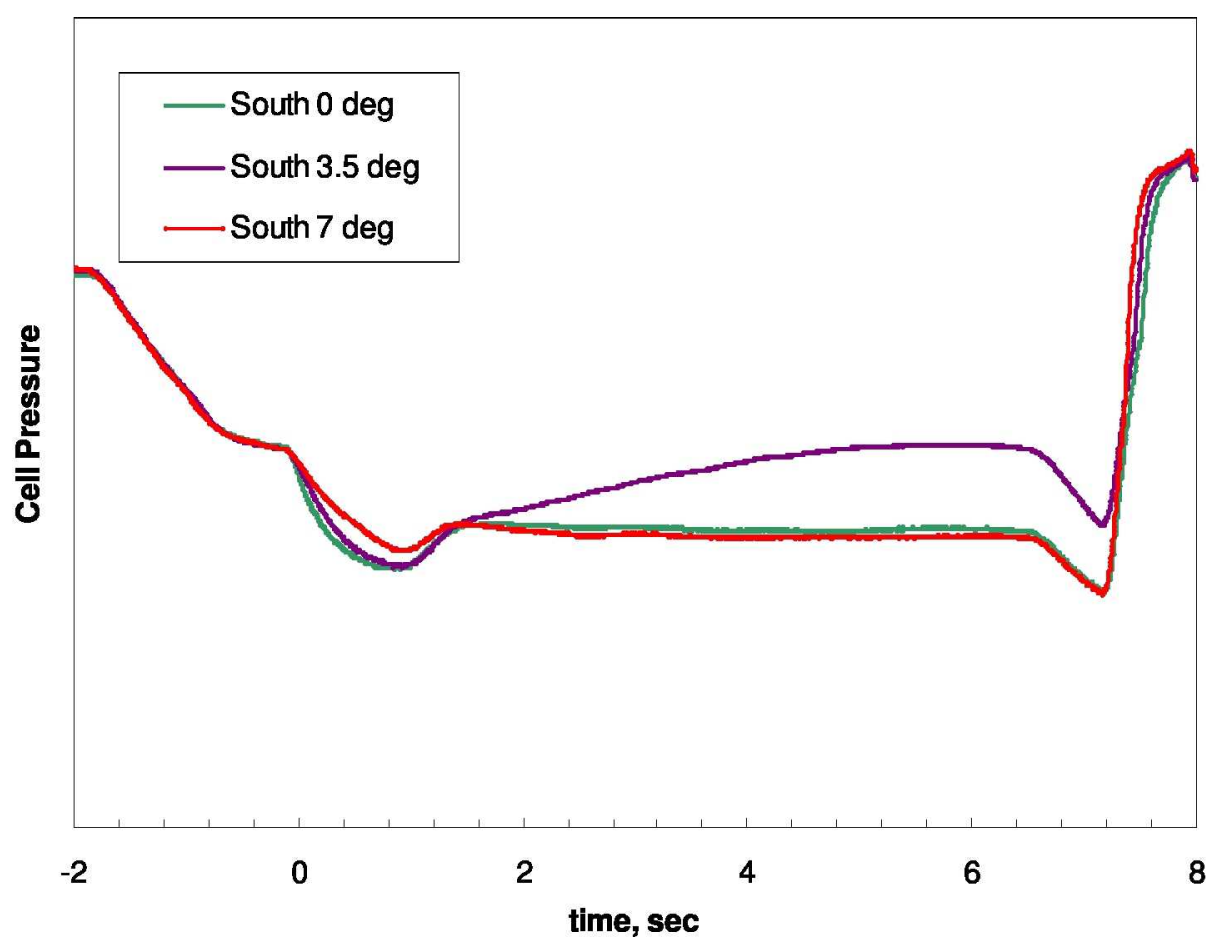

Figure 5. Test Cell Pressure at Different Gimbal Angles

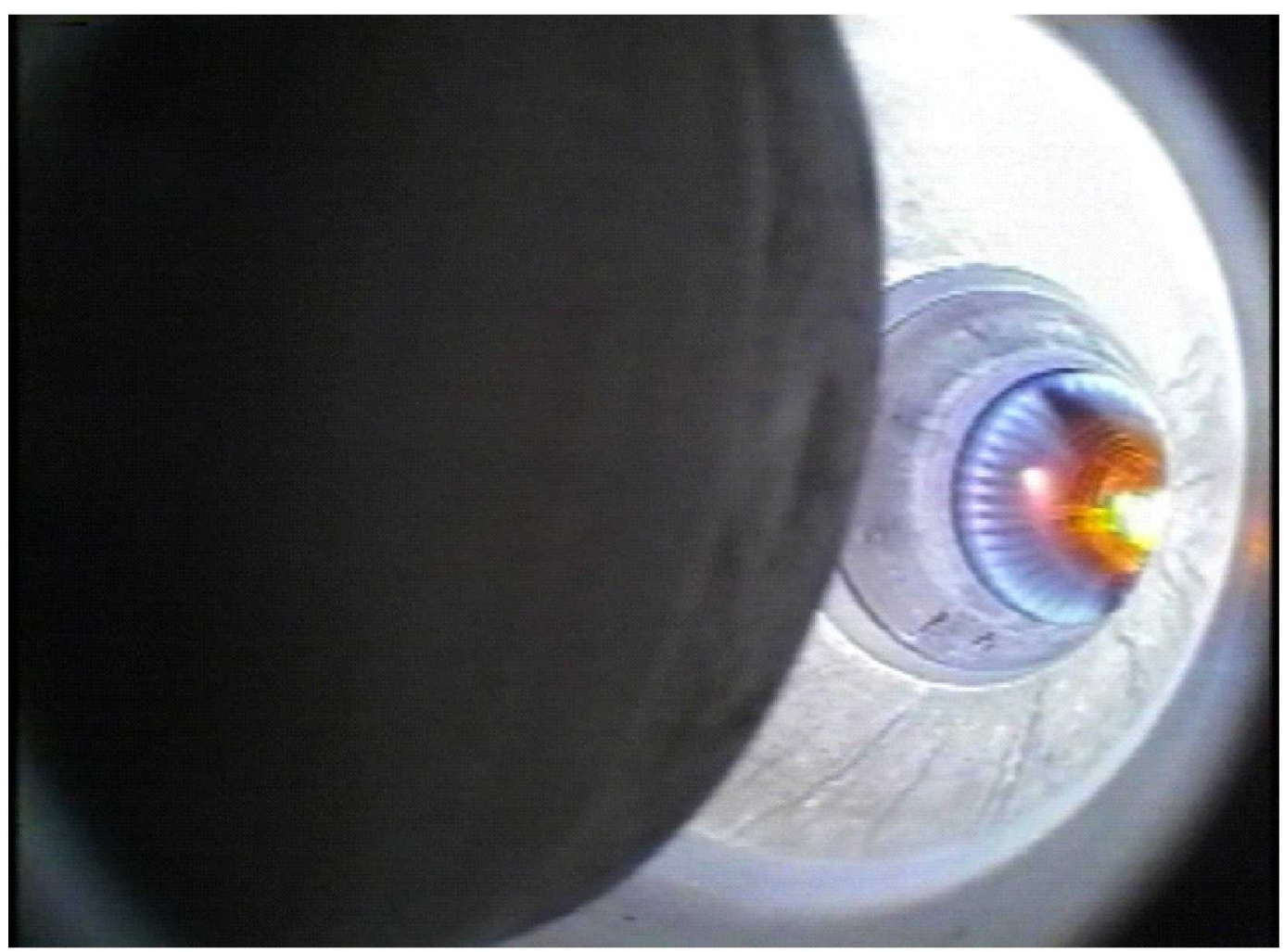

Figure 6. Photo of Rocket Plume Taken from Test Cell Camera 


\section{Heat Flux Tests}

High response thermocouple data has been taken for every hot fire test performed to obtain diffuser heat flux rates. The thermocouples initially were distributed evenly throughout the exhaust train identify the heat flux distribution. Due to limited data channels as described in the introduction, special tests were run to obtain detailed temperature data in high flux areas, namely the diffuser elbow and the rocket diffuser. The instrumentation used to obtain the temporal wall temperatures is described in Reference1. A description of the analysis techniques used and further results can be found in References 2 and 3.

\section{A. Special Rocket Diffuser Tests}

The rocket diffuser was heavily instrumented during gimbal to identify the peak heat flux location and magnitude. Twelve high response thermocouples were aligned axially along the rocket diffuser to obtain temporal wall temperature data. The rocket diffuser was also painted with temperature indicating paint to identify hot spots in the rocket diffuser. Figure 7 shows the layout of the rocket diffuser instrumentation ports. Figures 8 to 10 show the calculated rocket diffuser heat flux for the vertical orientation and gimbal angles of 3.5 and 7 degrees toward the south. Traces are identified by their corresponding thermocouple number, i.e. TC1 in Figures 8 to 10 correspond to row 1 in Figure 7. The traces indicate that the plume boundary moves farther upstream as the gimbal angle is increased. The plume boundary is between TC2 and TC3 without gimbal, between TC1 and TC2 at 3.5 degrees, and above TC1 at 7 degrees.

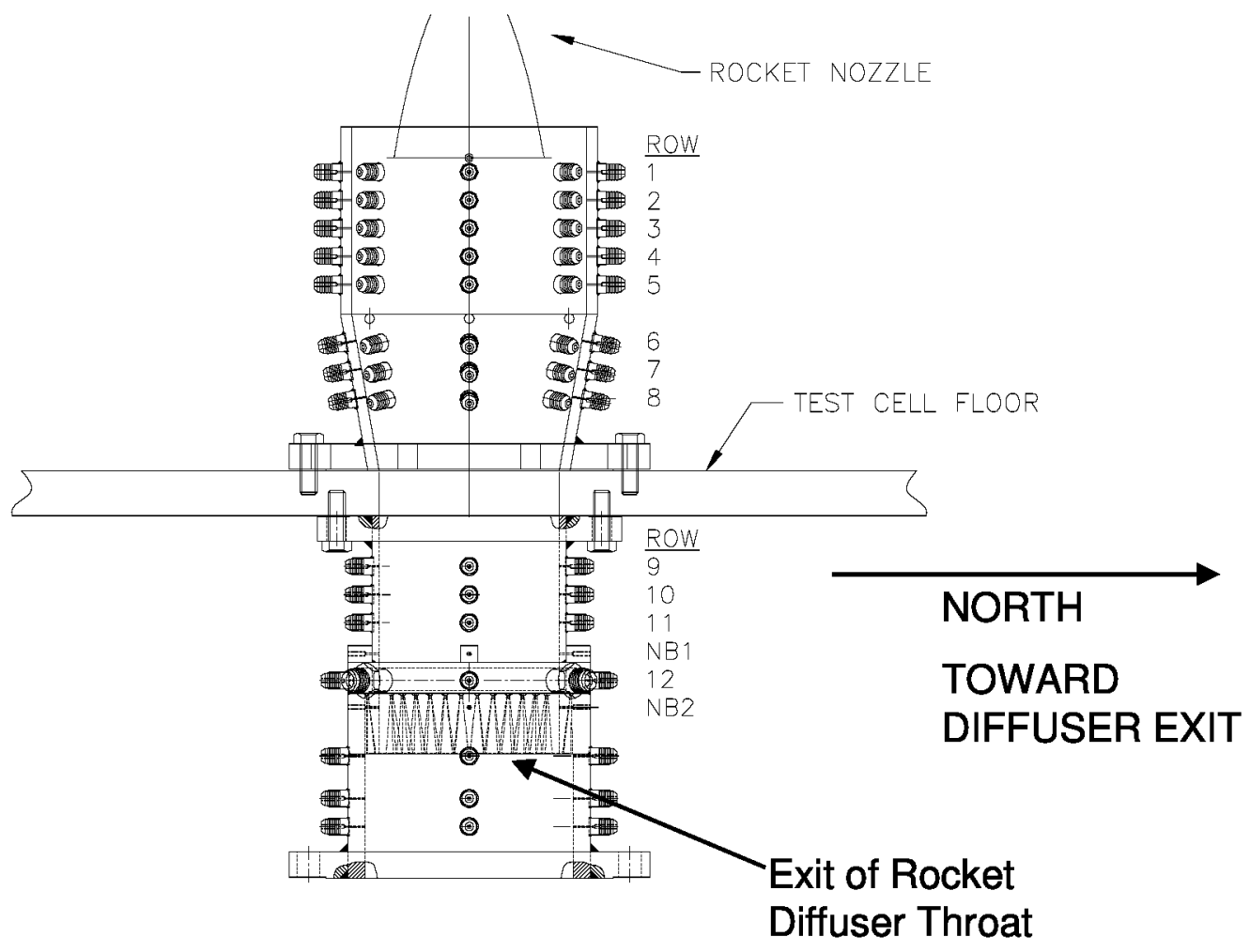

Figure 7. Rocket Diffuser Instrumentation Layout 


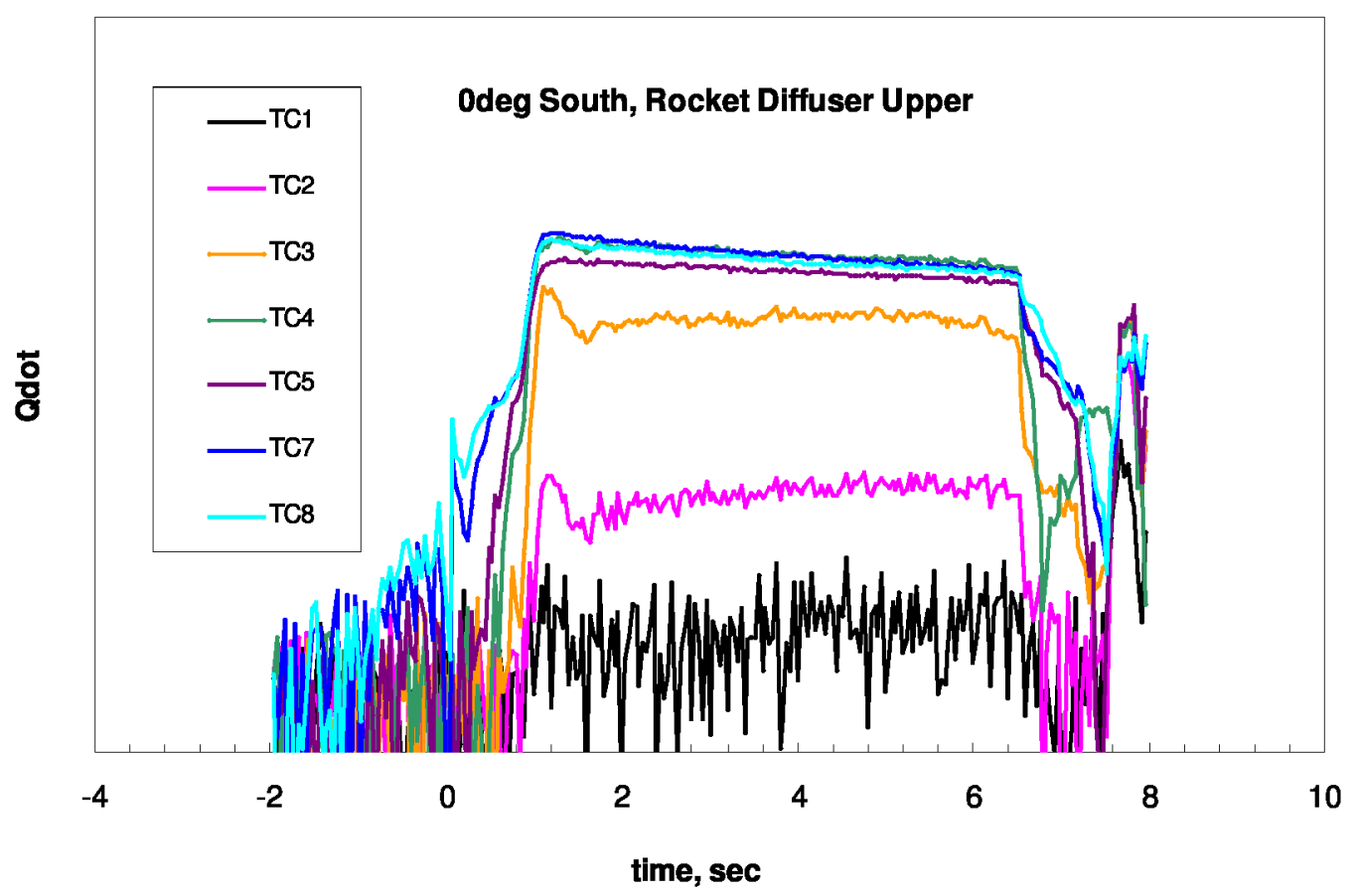

Figure 8. Rocket Diffuser Heat Flux without Gimbal

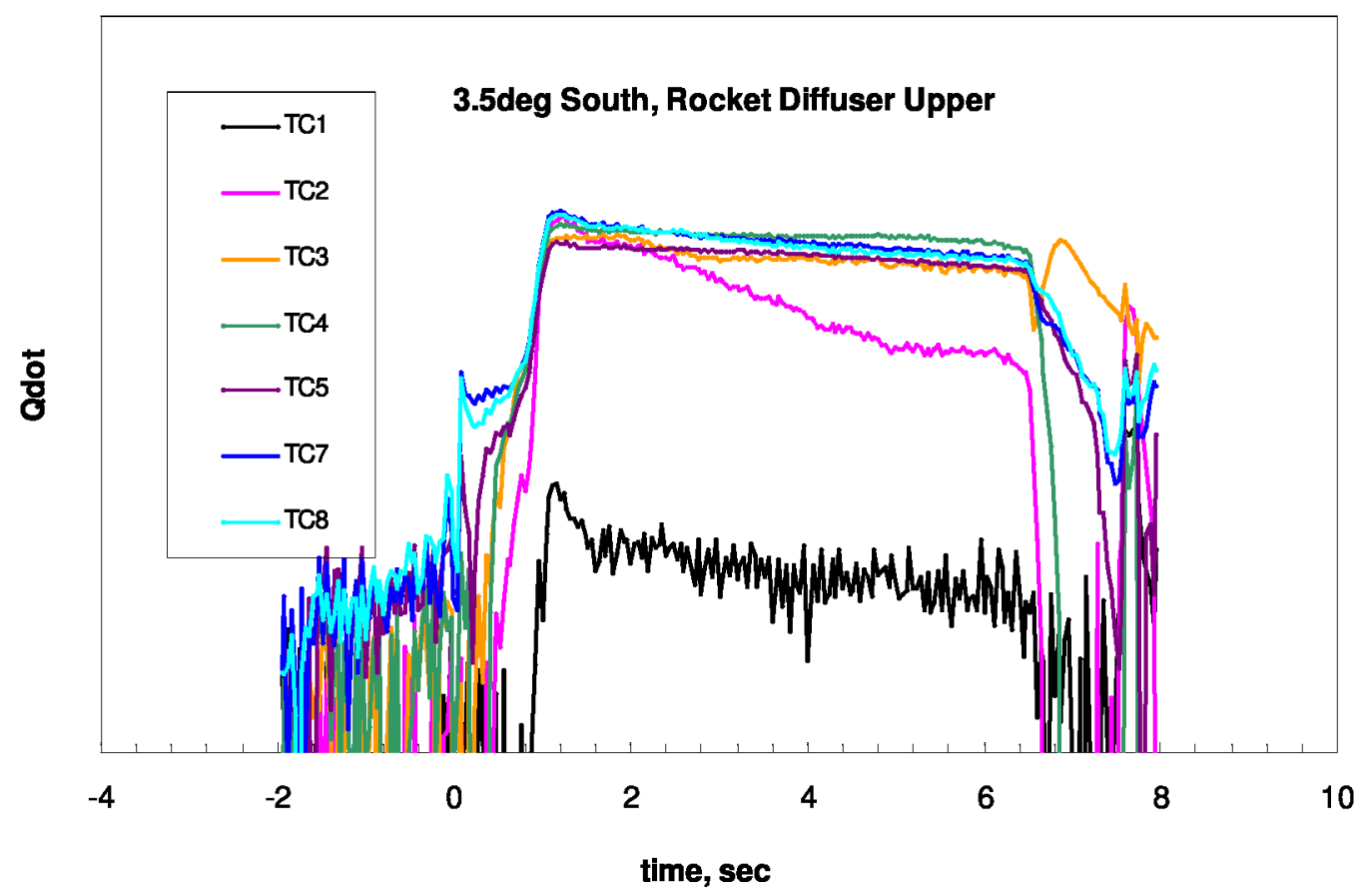

Figure 9. Rocket Diffuser Heat Flux at Gimbal Angle of 3.5 Degrees 


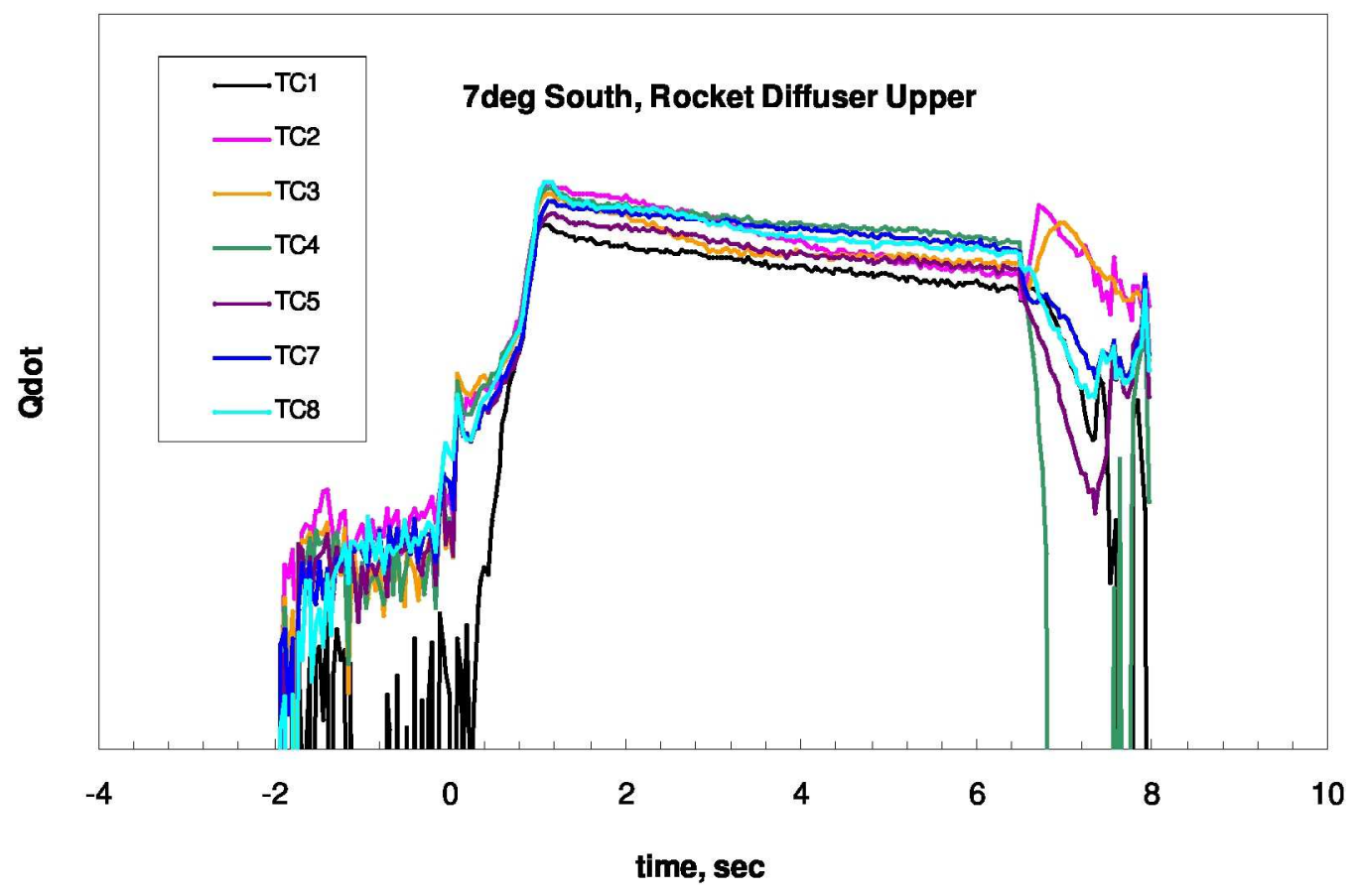

Figure 10. Rocket Diffuser Heat Flux at Gimbal Angle of 7.0 Degrees

Temperature indicating paint was used in the rocket diffuser during gimbal testing to give a qualitative indication of the relative heat flux and location of the rocket plume boundary. Figure 11 shows the temperature indicating paint in the rocket diffuser before and after gimbal testing. The paint can not give quanitative temperature because there is not enough exposure time to the hot rocket gas. However it does give qualitative indication that heat flux at plume impingement is not significantly higher than any value measured as indicated by the uniform discoloring of the diffuser.

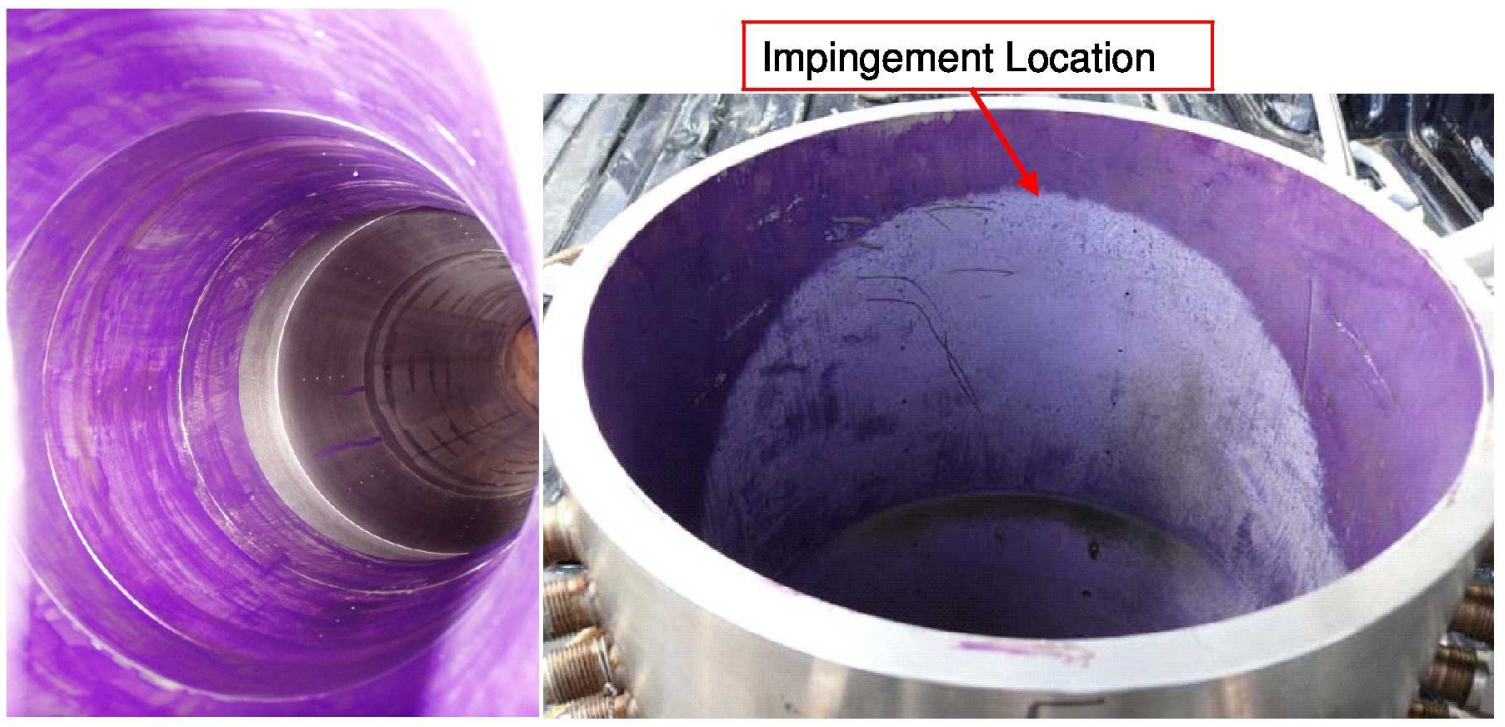

Figure 11. Temperature Indicating Paint in the Rocket Diffuser before (Left) and after (Right) Gimbal Testing 


\section{B. Special Elbow Tests}

The diffuser elbow experiences the highest heat flux of any component in the diffuser exhaust system. A special series of tests were run with all 29 available thermocouple channels used to obtain a high resolution temperature distribution in the elbow. Figure 12 shows the instrumentation port locations for the elbow heat flux tests.

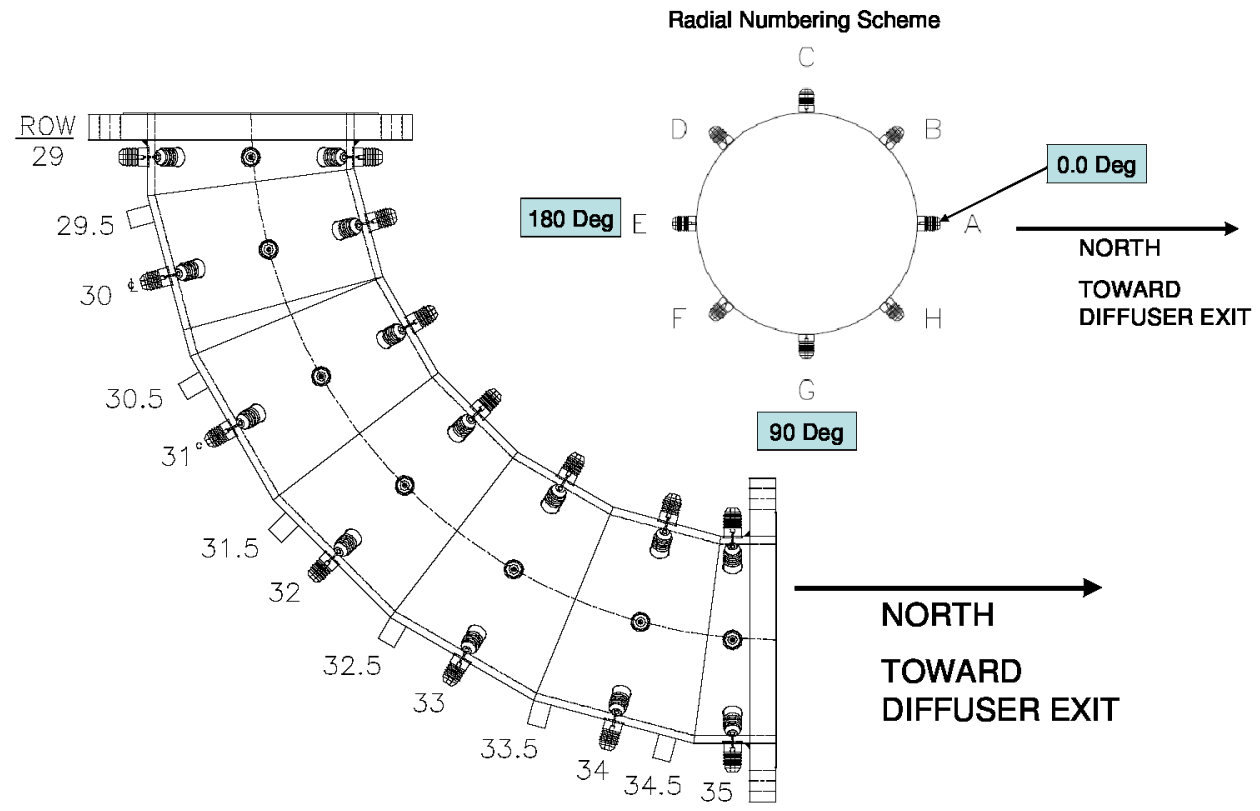

Figure 12. Instrumentation Port Identification on Diffuser Elbow.

All data was taken on the east half of the elbow. It is assumed that the heat flux is symmetric about the plane created by the horizontal and vertical diffuser axes. Figure 13 shows the heat flux results from one of the elbow heat flux tests with the JSS installed vertical. As expected, the peak heat flux occurs on the extrados of the elbow just downstream of the mid arc miter joint.

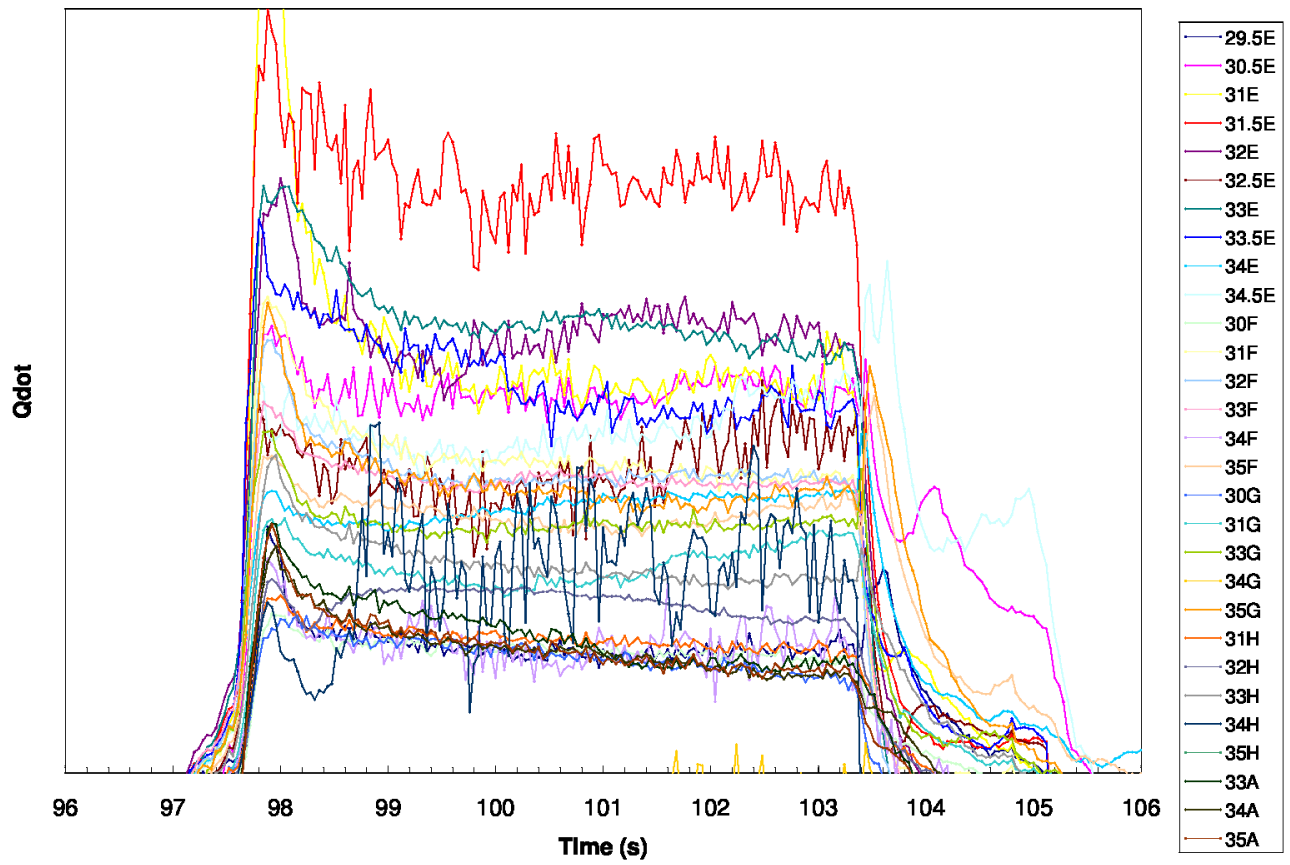

Figure 13. Heat Flux Results from Elbow Testing

American Institute of Aeronautics and Astronautics 
Temperature indicating paint was also used on the outside surface of the diffuser elbow early in the test program to give indication of the highest heat flux areas in the elbow. Once "hot spots" were located with the paint, high response thermocouple ports were added to measure the heat flux in those areas. Figure 14 shows the temperature indicating paint on the diffuser elbow before and after elbow testing.

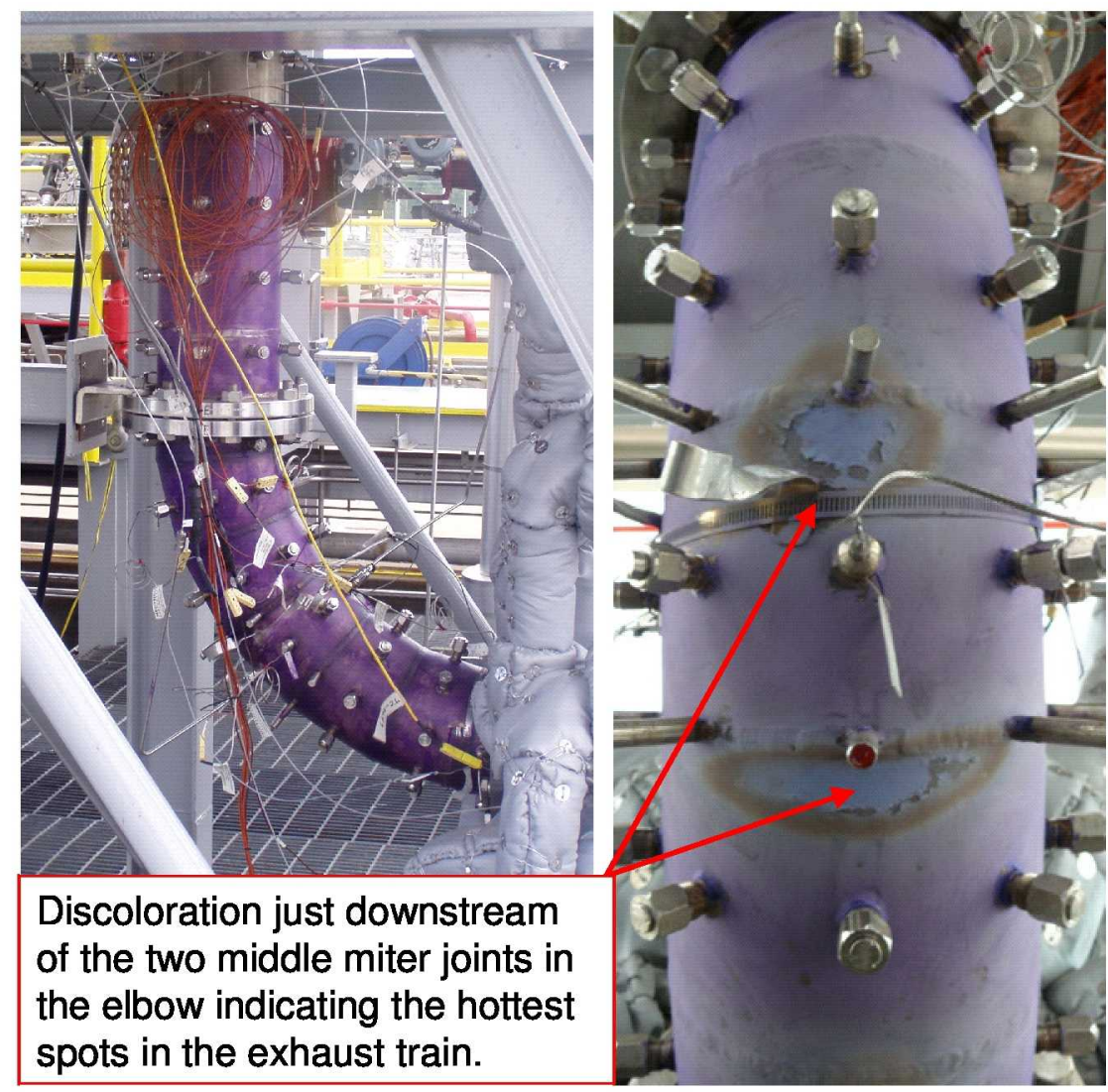

Figure 14. Temperature Indicating Paint on the Exterior of the Diffuser Elbow before (Left) and after (Right) Elbow Testing

\section{Conclusions}

A brief description of A3 subscale rocket hot fire testing and test results has been given. The aerodynamic performance of the rocket diffuser has proven to exceed the design suction pressure ratio requirement and all potential rocket gimbal angles. High response thermocouple measurements were taken in conjunction with all aerodynamic performance tests to quantify diffuser heat transfer rates. Additional heat transfer specific tests have also performed in the rocket diffuser and diffuser elbow. Future work is planned to revise this manuscript to expand the discussion of rocket diffuser performance and the analysis of heat transfer measurements.

\section{References}

\footnotetext{
${ }^{1}$ Saunders, G.P., "A3 Subscale Diffuser Test Article Design”, AIAA-2009-5010, 2009.

${ }^{2}$ Yen, J., Saunders, G.P., and Wagner, D.A., "Transient Heat Load Estimate for the A3 Supersonic Rocket Diffuser Using Surface Temperature Measurement", AIAA-2009-5012, 2009.

${ }^{3}$ Yen, J., Saunders, G.P., and Wagner, D.A., "Error Analysis of the Surface Heat Flux Calculation for the A3 Supersonic Diffuser", AIAA-2009-5011, 2009.

${ }^{4}$ Saunders, G.P., Raines, N.G., and Varner, D.G., "Design, Activation, and Operation of the J2-X Subscale Simulator (JSS)", AIAA-2009-5098, 2009.

'Saunders, G.P., and Wagner, D.A., “A3 Subscale Steam Ejector Performance Testing”, AIAA-2009-5100, 2009.
} 